\title{
Degradation of phenolic acids by gamma radiation as model compounds of cork wastewaters
}

\author{
J. Madureira ${ }^{a}$, L. Barros ${ }^{b}$, R. Melo ${ }^{a}$, S. Cabo Verde ${ }^{a, *}$, Isabel C.F.R. Ferreira ${ }^{b}$, F.M.A. Margaça ${ }^{a}$ \\ ${ }^{\text {a } C e n t r o ~ d e ~ C i e ̂ n c i a s ~ e ~ T e c n o l o g i a s ~ N u c l e a r e s ~(C ~}{ }^{2}$ TN), Instituto Superior Técnico, Universidade de Lisboa, E.N. 10 ao km 139.7, $2695-066$ Bobadela LRS, Portugal \\ ${ }^{\mathrm{b}}$ Centro de Investigação de Montanha (CIMO), Instituto Politécnico de Bragança, Campus de Santa Apolónia, 5301-253 Bragança, Portugal
}

\section{H I G H L I G H T S}

- The radiolytic degradation of four phenolic compounds from cork wastewaters was studied under different $\mathrm{pH}$ and atmospheres.

- The degradation of the compounds was more evident in isolated than in the mixture solutions.

- In the quaternary mixture, it were achieved higher degradation rates under irradiation with $\mathrm{N}_{2} \mathrm{O}$.

- Some of the compounds are a degradation product of the others.

- 2,3,4-Trihydroxybenzoic acid and methyl gallate were identified as radiolytic products of the phenolic acids.

\section{A R T I C L E I N F O}

\section{Keywords:}

Phenolic acids

Gamma radiation

Radiolytic degradation

Cork wastewaters

\section{G R A P H I C A L A B S T R A C T}

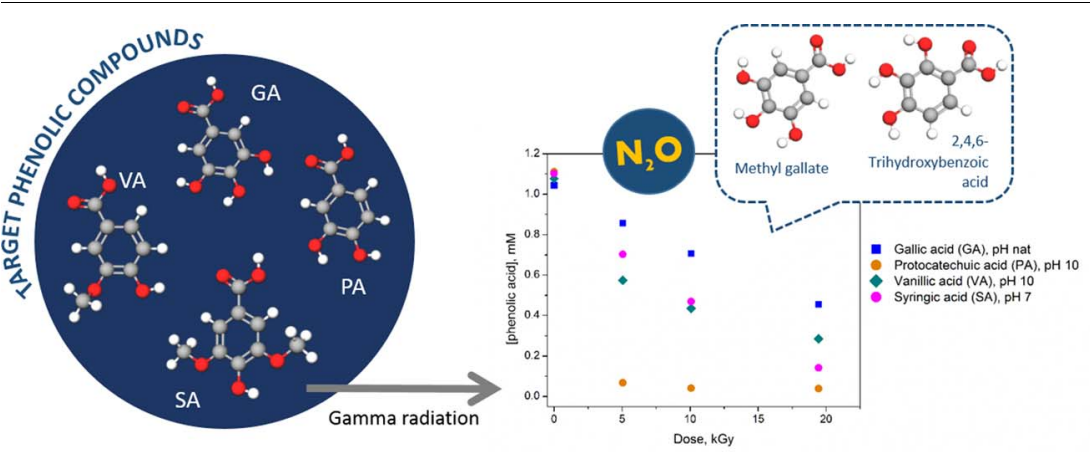

\begin{abstract}
A B S T R A C T
The degradation by gamma radiation of four phenolic compounds (gallic acid, protocatechuic acid, vanillic acid and syringic acid) present in cork wastewaters was studied in several treatment conditions. The irradiations were performed under different $\mathrm{pH}$ (natural, 3, 7 and 10) and atmospheres (aerated, $\mathrm{N}_{2} \mathrm{O}$ and $\mathrm{O}_{2}$ ) for isolated and aqueous mixture solutions of standard phenolic acids. The degradation of the compounds was higher in isolated than in the mixture solutions indicating a protective effect in the quaternary mixture solution. The saturation with $\mathrm{N}_{2} \mathrm{O}$ promoted the highest degradation rates for all phenolic acids in the mixture. However, at natural $\mathrm{pH}$ and in air it was achieved degradation efficiencies $>50 \%$ for gallic, vanillic and syringic acids in isolated and mixture solutions for a treatment dose of $20 \mathrm{kGy}$. It was verified that some of the compounds are a degradation product of the others, for example gallic acid was found to be a radiolytic product of syringic, vanillic and protocatechuic acids. Two different compounds were identified as radiolytic products of the studied phenolic acids, and their fragmentation pathways were proposed. The results highlighted that ionizing radiation could be used as clean technology for pollutants degradation using doses of $20 \mathrm{kGy}$.
\end{abstract}

\section{Introduction}

In cork industry, the wastewater produced during the cooking process is characterized by low $\mathrm{pH}$ and biodegradability, and high concentration of organic compounds as phenolics and other corkwood extracts such as tannins and 2,4,6-trichloroanisol. These compounds are known to be difficult to degrade by conventional methods [1].

Taking into account this issue, advanced oxidation processes (AOPs)

\footnotetext{
* Corresponding author.

E-mail address: sandracv@ctn.tecnico.ulisboa.pt (S. Cabo Verde).
} 
appeared as alternative technologies to eliminate the recalcitrant compounds of cork wastewaters. AOPs are considered clean technologies for the treatment of polluted waters as they produce high reactive species, such as hydroxyl radical $\left(\mathrm{OH} \cdot\right.$, superoxide $\left(\mathrm{O}_{2}{ }^{-}\right)$and hydrogen peroxide $\left(\mathrm{H}_{2} \mathrm{O}_{2}\right)$, which will react with the organic pollutants [2]. These technologies can degrade organic pollutants including phenolics into less complex compounds, leading to their complete mineralization in the ideal scenario.

Several reports have been published about the treatment of cork wastewater, including ozonation [3,4], Fenton's reagent [5,6], membrane separation [7-9] and other methods using the combination of two or more oxidation processes $[10,11]$. At the same time, the ionizing radiation is being considered an emergent technology for wastewater treatments with the capacity to reduce the impact of chemical and biological pollution of effluents in the environment $[12,13]$.

Among others, the major phenolic compounds present in cork wastewater are gallic acid, protocatechuic acid, vanillic acid and syringic acid $[14,15]$. Phenolic compounds belong to one of the largest groups of environmental pollutants due to their wide applications in agro-industrial wastewaters (from cork and others such as olive oil mills and wine distilleries) and as antimicrobial agents [16]. The negative impact of these compounds on the environment and human health is related to its high toxicity and non-biodegradability, being defined as priority pollutants. Several organizations have created regulations for phenolic compounds in drinking water and the environment $[17,18]$. Therefore, the elimination of phenolic compounds from wastewater is a current societal challenge. Some studies about the use of AOPs to degrade these compounds have been reported [19-23]. Benitez and the co-workers studied the degradation of the vanillic and syringic acids in a mixture with caffeic and p-coumaric acids by single UV radiation and the combination of ozone and UV radiation [22] and the first ones were the less degraded with different temperatures and $\mathrm{pH}$. Also, Benitez studied the degradation of protocatechuic acid by ozonation [24,25], ozonation/UV radiation and $\mathrm{H}_{2} \mathrm{O}_{2} / \mathrm{UV}$ radiation [21] and the kinetic rate constants were determined as a function of temperature and $\mathrm{pH}$. The oxidation of gallic acid was also studied $[19,23]$ to evaluate the possibility to reduce the problematic phenolic fraction in winery wastewaters and, comparing with other combined AOPs, the photo-Fenton process was found to be the most effective process in removing gallic acid from aqueous solutions. In addition, Melo et al. [26] demonstrated the use of gamma radiation as an advantageous tool for the degradation of phenolic compounds and that gallic acid was degraded by several paths, first to aliphatic and other aromatic compounds and finally to aliphatic polycarboxylic acids. Otherwise, for cork wastewater, this technology could specifically bring added-value to this effluent by increasing the antioxidant activity [27], while decreasing the organic matter [28]. Nevertheless, a comprehensive knowledge on the radiolytic pathway of cork phenolic compounds is not yet available, that could bring new insights on the use of ionizing radiation in cork wastewater treatment process.

The radiolysis of water due to ionizing radiation produce several oxidizing species described in Eq. (1) [29].

$\mathrm{H}_{2} \mathrm{O} \rightarrow \cdot \mathrm{OH}(2.7)+\mathrm{e}_{\mathrm{aq}}{ }^{-}(2.6)+\mathrm{H}^{\cdot}(0.55)+\mathrm{H}_{2}(0.45)+\mathrm{H}_{2} \mathrm{O}_{2}(0.71)$
$+\mathrm{H}_{3} \mathrm{O}^{+}(2.6)$

The primary reactive species are the hydroxyl radicals, hydrated electrons and hydrogen atom. The values in brackets are the radiation chemical yield, G-value, defined as the number of product molecules formed (or initial molecules changed) for every $100 \mathrm{eV}$ of absorbed energy, which are $\mathrm{pH}$ dependent. At acidic $\mathrm{pH}$, the hydrated electron react with the hydrogen ion and is converted to a hydrogen atom, resulting in a reduction of the effective concentration of $\mathrm{OH} \cdot$ radicals and leading to a decrease in the efficacy of compounds degradation under these conditions. Normally, the degradation efficiency decreases at alkaline conditions $(\mathrm{pH}>10)$ and at strong acid conditions $(\mathrm{pH}<2.0)$, due a reduction in the yield of formation of $\mathrm{OH} \cdot$ and $e_{a q}^{-}$radicals, respectively. In turn, weak acid to neutral conditions point out to favor radiolytic degradation, considering the increased yields of formation of all primary reactive species.

The aim of this work is to study the radiolytic degradation of cork phenolic compounds by High Performance Liquid Chromatography (HPLC), Diode Array Detector (DAD) and Electrospray Ionisation Mass Spectrometry (ESI/MS). Four phenolic acids (gallic acid, protocatechuic acid, vanillic acid and syringic acid) were selected as model compounds of the wastewater from cork industry to be degraded by gamma radiation under different conditions ( $\mathrm{pH}$ and irradiation atmosphere). Isolated and mixture aqueous solutions of phenolic acids were used in order to investigate separately the behavior of the decomposition of each compound and simulating a real situation of cork wastewater. The different irradiation atmospheres were used in order to promote the formation of specific radical species. In the presence of oxygen, the reducing radicals $\mathrm{H} \cdot$ and $e_{a q}^{-}$are converted into $\mathrm{HO}_{2}{ }^{\cdot}$ and $\mathrm{O}_{2}{ }^{-}-$. On the other hand, to avoid the influence of oxygen and to enhance the $\mathrm{OH}$. radical yield, radiolysis in the presence of $\mathrm{N}_{2} \mathrm{O}$ was performed.

\section{Experimental}

\subsection{Chemicals}

Gallic acid (3,4,5-trihydroxybenzoic acid), protocatechuic acid (3,4dihydroxybenzoic acid), syringic acid (4-hydroxy-3,5-dimethoxybenzoic acid) and sodium acetate trihydrate were purchased from Sigma (St Louis, USA). Vanillic acid (4-hydroxy-3-methoxybenzoic acid) was commercially available from Fluka (Buchs, Switzerland). Acetic acid with $>99.8 \%$ purity, hydrochloric acid and sodium hydroxide were provided by Riedel-de Haën (Seelze, Germany). HPLC grade acetonitrile and sodium bicarbonate were purchased from Carlo Erba (Val de Reuil, France). Formic acid was provided from Panreac Química SA (Barcelona, Spain) and di-Sodium hydrogen phosphate was provided from Merck (USA).

Water was treated by a Milli-Q water purification system (Merck Millipore, USA).

\subsection{Samples preparation}

To study the influence of the $\mathrm{pH}$ on the degradation of phenolic acids, pure and mixed buffered solutions of the four phenolic acids at a concentration of $1 \times 10^{-3} \mathrm{M}$ were prepared at different $\mathrm{pH}$ (natural, 3, 7 and 10). The natural $\mathrm{pH}$ solutions of gallic acid, protocatechuic acid, vanillic acid, syringic acid (Fig. 1) and the mixture solution were prepared using ultrapure water and the measured $\mathrm{pH}$ was: 3.84, 3.93, 3.82, 3.76 and 3.50, respectively. The degradation studies were performed for isolated compounds solutions and mixture solution of the four phenolic acids. Additionally, three different atmospheres were used in the preparation of solutions: i) without deaeration; ii) saturated with oxygen $\left(\mathrm{O}_{2}\right)$ and iii) saturated with nitrous oxide $\left(\mathrm{N}_{2} \mathrm{O}\right) . \mathrm{O}_{2}$ and $\mathrm{NO}_{2}$ gases were supplied by Air Liquide. The solutions were saturated during 30 min without previous deaeration and irradiated immediately after preparation.

\subsection{Irradiation experiments}

Irradiation experiments were carried out in a Co-60 experimental chamber (model Precisa 22, Graviner Lda, UK, 1971, with four cobalt60 sources with a total activity of $107 \mathrm{Tbq}, 2.9 \mathrm{kCi}$, May 2017) located at Instalação de Radiações IonizanteS (IRIS) from Centro de Ciências e Tecnologias Nucleares (C2TN) of IST, Universidade de Lisboa. All irradiations were conducted at room temperature at a dose rate of $1.5 \mathrm{kGy} \mathrm{h}^{-1}$. The solutions of phenolic acids in glass vials $(3 \mathrm{~mL})$ were treated with gamma radiation at doses ranging from 4.7 to $20.2 \mathrm{kGy}$. The samples were placed in an automatic rotation system to guarantee 
Gallic acid<smiles>O=C(O)c1cc(O)c(O)c(O)c1</smiles>

Vanillic acid<smiles>COc1cc(C(=O)O)ccc1O</smiles>

Protocatechuic acid<smiles>O=C(O)c1ccc(O)c(O)c1</smiles>

Syringic acid

Fig. 1. Structures of the investigated phenolic acids.

a)

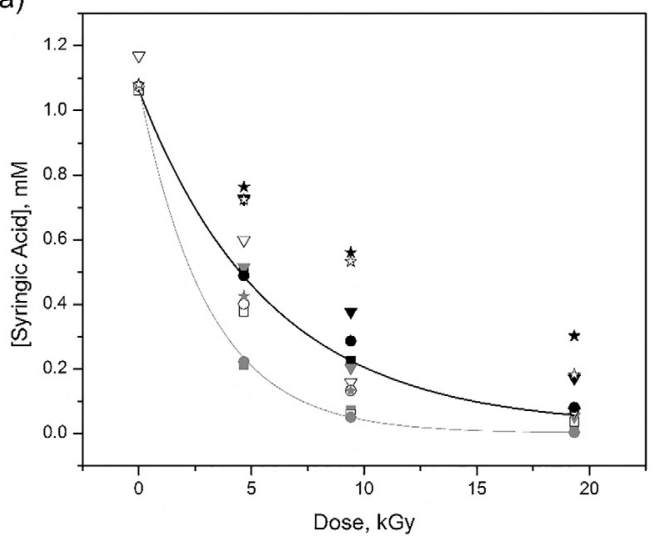

b)

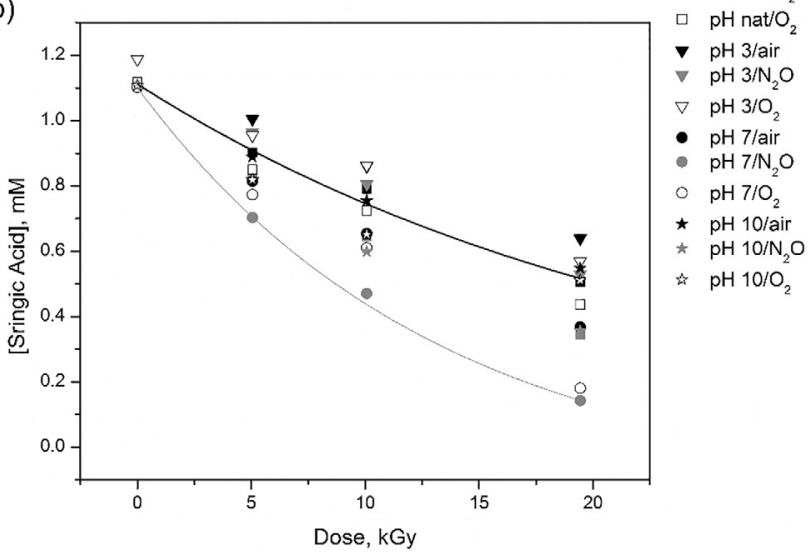

Fig. 2. Syringic acid average concentration decay $(n=2)$ by gamma radiation under different $\mathrm{pH}$ and atmosphere conditions: a) isolated compound solution and b) quaternary mixture solution. Exponential fit: black line - aerated solution at natural pH; grey line best degradation condition.

dose uniformity (DUR $=1.1$ ). The absorbed doses were measured by routine dosimeters [30]. The local dose rate had been previously determined by Fricke method [31]. a)

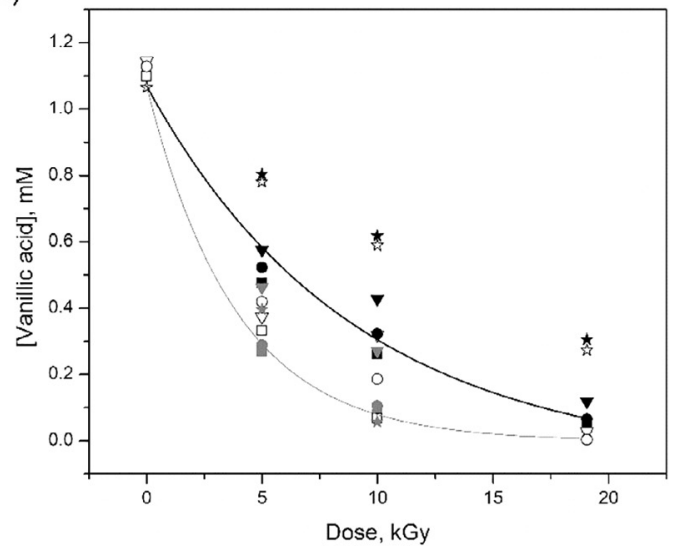

b)

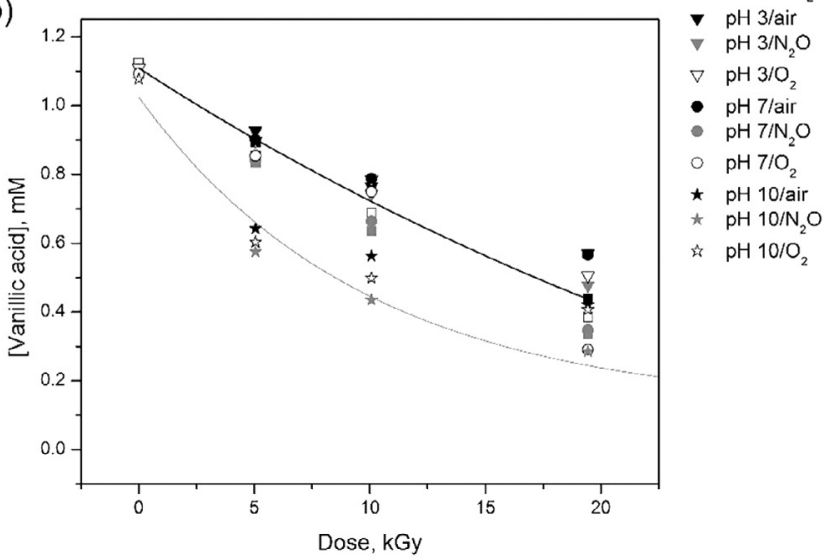

Fig. 3. Vanillic acid average concentration decay $(n=2)$ by gamma radiation under different $\mathrm{pH}$ and atmosphere conditions: a) isolated compound solution and b) quaternary mixture solution. Exponential fit: black line - aerated solution at natural pH; grey line best degradation condition.

\subsection{Analytical procedures}

Before and after irradiation, the $\mathrm{pH}$ of the solutions (isolated and mixed) was measured by potentiometer (Radiometer, model PHM210) previously calibrated with buffered solutions.

The degradation of phenolic acids was analyzed by High Performance Liquid Chromatography (HPLC) (Prominence CBM 20-A, Shimadzu, Japan) with UV-DAD detector. The HPLC column was a Merck Purospher STAR RP-18e $(5 \mu \mathrm{m}, 250 \mathrm{~mm}, 4.0 \mathrm{~mm})$ and the detection was made at $280 \mathrm{~nm}$. The mobile phase used was: A $(90 \%(\mathrm{v} / \mathrm{v})$ ultra-pure water with $0.1 \%$ formic acid) and B (10\% acetonitrile solution). The column temperature was maintained at $298 \mathrm{~K}$, the injection volume was $20 \mu \mathrm{L}$ and the flow rate was $1 \mathrm{~mL} \mathrm{~min}^{-1}$. For quantification purposes, a calibration plot was performed under the experimental conditions used.

\subsection{Identification of radiolytic products}

The phenolic acids products were detected using a LC-DAD-ESI/MSn (Dionex Ultimate 3000 UPLC, ThermoScientific, San Jose, CA, USA). Double online detection was performed using a Diode Array Detector (DAD) with 280, 330, 370 as preference wavelengths and in a mass spectrometer (MS). The MS detection was performed in negative mode, using a Linear Ion Trap LTQ XL mass spectrometer (ThermoFinnigan, San Jose, CA, USA) equipped with an ESI source, which was connected to the HPLC system via the DAD cell outlet [32]. Data acquisition was carried out with Xcalibur $^{\circledast}$ data system (ThermoFinnigan, San Jose, CA, USA). The separation was achieved using a Waters Spherisorb S3 ODS-2 

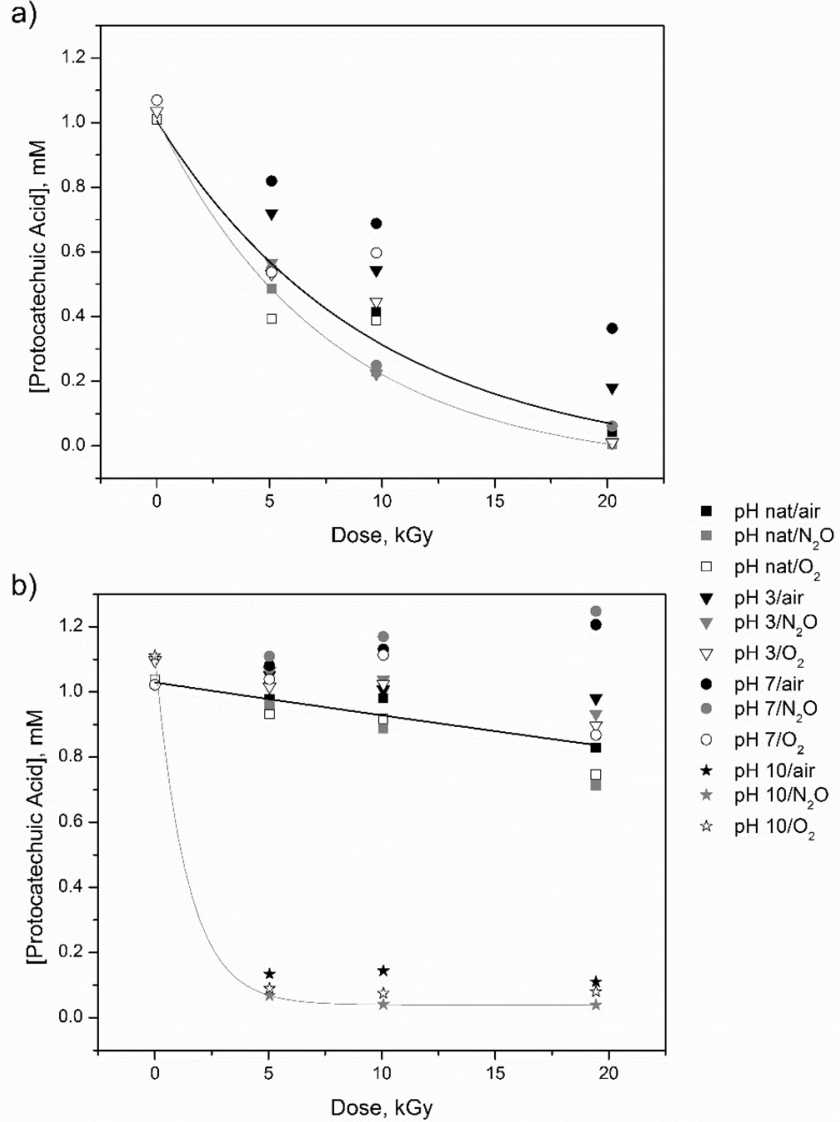

Fig. 4. Protocatechuic acid average concentration decay $(n=2)$ by gamma radiation under different $\mathrm{pH}$ and atmosphere conditions: a) isolated compound solution and b) quaternary mixture solution. Exponential fit: black line - aerated solution at natural $\mathrm{pH}$; grey line - best degradation condition.

$\mathrm{C}_{18}$ column $(3 \mu \mathrm{m}, 4.6 \times 150 \mathrm{~mm}$, Waters, Milford, MA, USA) thermostatted at $308 \mathrm{~K}$, using a gradient elution with the following solvents: $0.1 \%$ formic acid in water (A) and acetonitrile (B). The elution gradient established was $10 \%$ B for $5 \mathrm{~min}, 10 \%$ B to $15 \%$ B over $5 \mathrm{~min}, 15-30 \%$ B over $15 \mathrm{~min}, 30-50 \%$ B over $10 \mathrm{~min}, 50 \%$ B for $10 \mathrm{~min}, 50-10 \%$ B for $10 \mathrm{~min}$ and re-equilibration of the column $(10 \mathrm{~min})$, using a flow rate of $0.5 \mathrm{~mL} \mathrm{~min}^{-1}$. MS detection with electrospray ionization was performed with the following conditions: sheath gas $\left(\mathrm{N}_{2}, 50 \mathrm{psi}\right)$; source temperature $325^{\circ} \mathrm{C}$; spray voltage $5 \mathrm{kV}$; capillary voltage $-20 \mathrm{~V}$; tube lens offset voltage $-66 \mathrm{~V}$; collision energy 35 arbitrary units. The full scan data were collected from $m / z 100$ to 1500 .

Compounds were identified comparing the obtained information (retention times, UV-vis and mass spectra) with available data reported in the literature and by comparison with standard compounds, when available.

\subsection{Data analysis}

Origin software version 7.5 (OriginLab Corporation, Northampton, USA) was used for data analysis. Confidence intervals for means values were estimated considering a significance level of $p<0.05$ and the number of replicates for each assay. The results were analyzed using one-way analysis of variance (ANOVA) followed by Tukey's HSD test with $\alpha=0.05$.
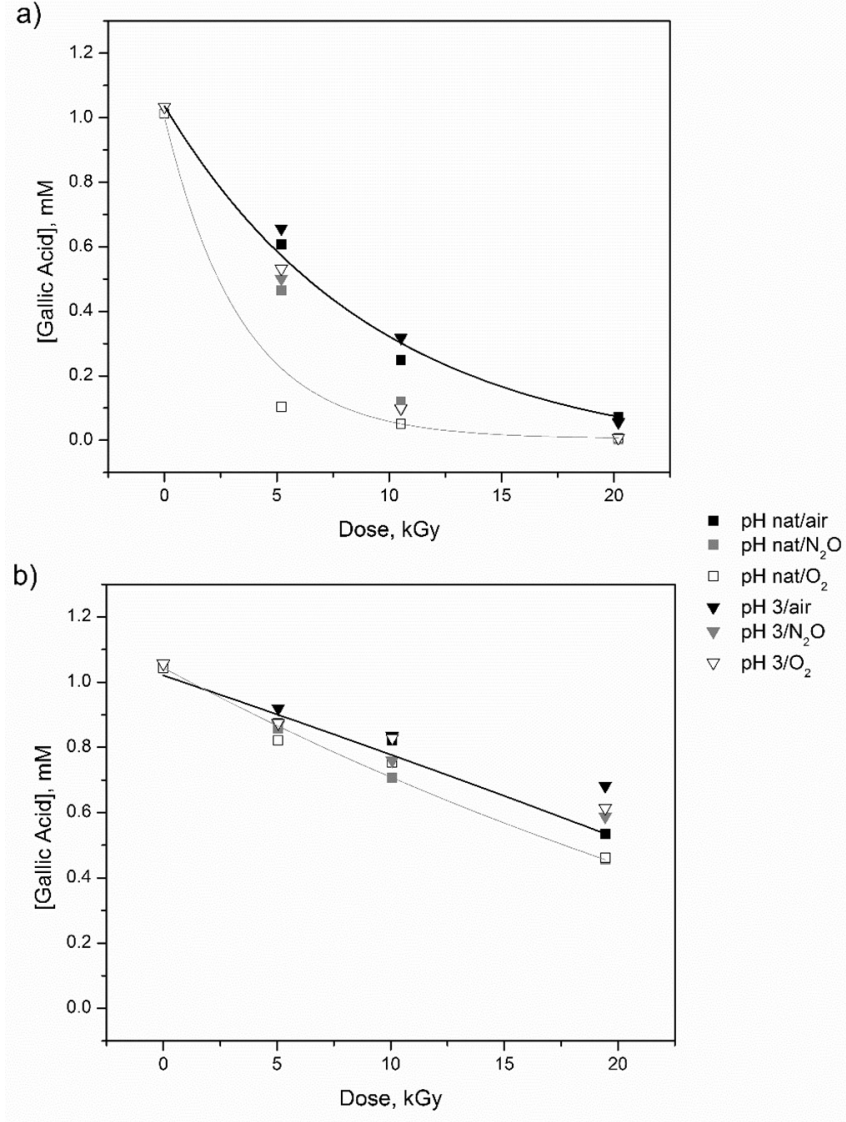

Fig. 5. Gallic acid average concentration decay $(n=2)$ by gamma radiation under different $\mathrm{pH}$ and atmosphere conditions: a) isolated compound solution and b) quaternary mixture solution. Exponential fit: black line - aerated solution at natural $\mathrm{pH}$; grey line best degradation condition.

\section{Results and discussion}

\subsection{Degradation of phenolic acids}

The $\mathrm{pH}$ was measured in all the samples, before and after gamma irradiation, and the obtained values were constant for all the solutions after the treatment.

The degradation of phenolic compounds by gamma radiation was studied as isolated compounds and in a quaternary mixture to evaluate the effect of the other compounds on the radiolytic degradation. Also, the degradation was investigated under different $\mathrm{pH}$ and irradiation atmospheres, to understand the factors that could influence the radiolytic pathways of the target phenolic acids.

To analyse the effect of the studied irradiation atmospheres, Figs. 2-5 display the results of concentration decay of syringic acid, vanillic acid, protocatechuic acid and gallic acid, respectively, for both isolated and mixture solutions, as a function of the gamma radiation dose, at different $\mathrm{pH}$ and atmosphere conditions.

The degradation trends were similar for syringic acid, vanillic acid and gallic acid, which were higher in isolated compounds solutions than in the mixture solutions for all atmospheres (Figs. 2, 3 and 5), underlining a protective effect of the compounds in the quaternary mixture. Protocatechuic acid degradation is an exception, since the decay trend in the mixture solution is not similar to the other compounds (Fig. 4). From Figs. 2a-5a it can also be verified that there was no significant difference on the radiolytic degradation of the isolated compounds between the simplest condition (natural $\mathrm{pH}$ and in air) and the best degradation condition at the higher radiation dose $(20 \mathrm{kGy})$. In the mixture solutions (Figs. 2b-5b), however, the influence of the 


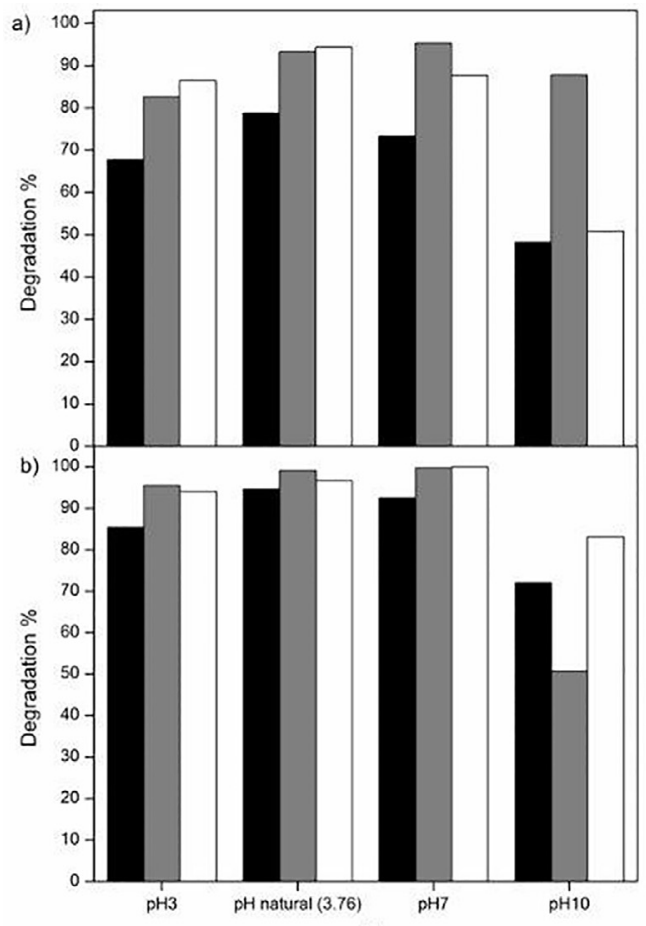

$\mathrm{pH}$

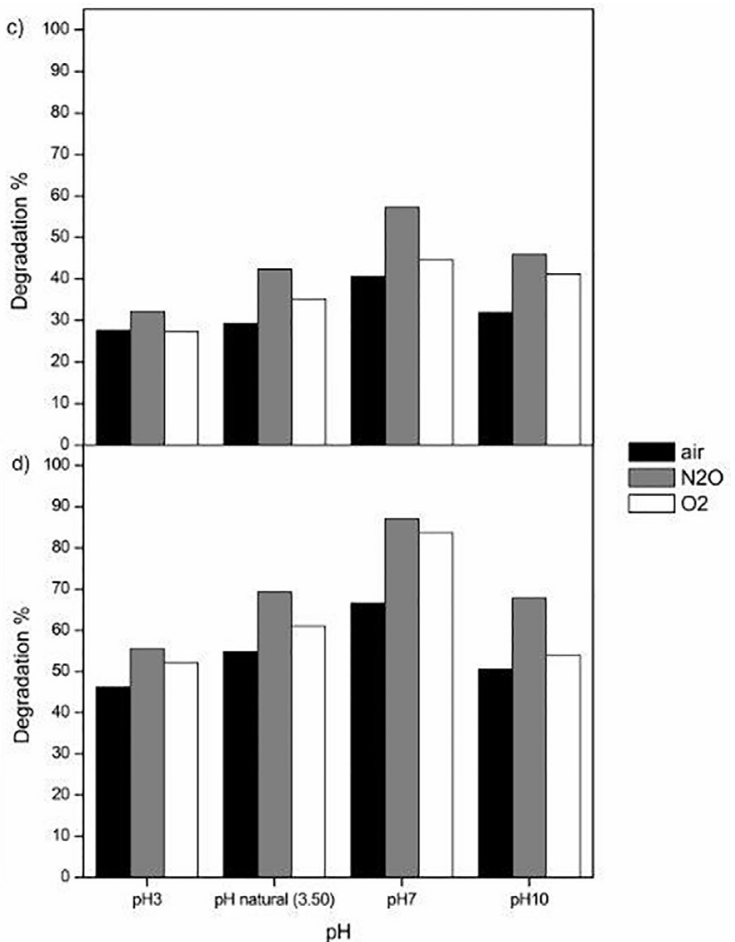

$\mathrm{pH}$

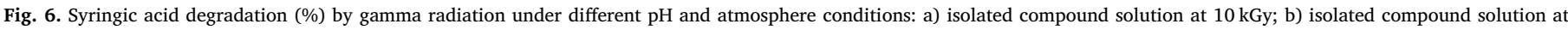
$20 \mathrm{kGy}$; c) quaternary mixture solution at $10 \mathrm{kGy}$; d) quaternary mixture solution at $20 \mathrm{kGy}$.
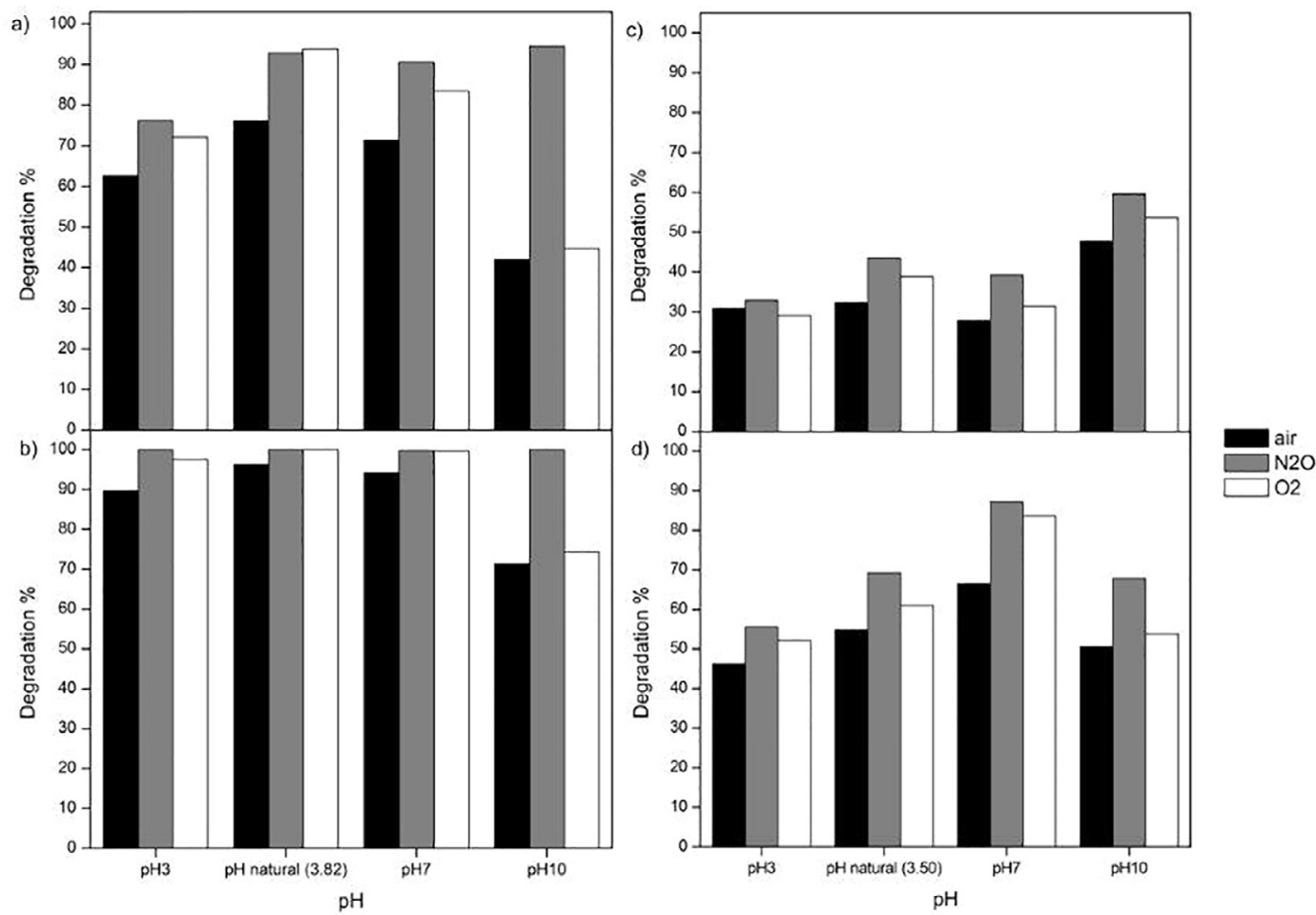

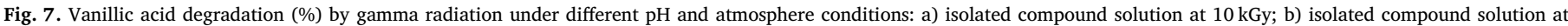
$20 \mathrm{kGy}$; c) quaternary mixture solution at $10 \mathrm{kGy}$; d) quaternary mixture solution at $20 \mathrm{kGy}$.

irradiation atmosphere on the compounds degradation was observed.

The radiolytic degradation of the syringic acid was higher in isolated compounds solutions than in the mixture solutions for all atmospheres (Fig. 2), which could be explained by the protective effect of the compounds in the quaternary mixture, as mentioned above. The syringic acid degradation in the mixture solution was higher at $\mathrm{pH} 7$ in saturated $\mathrm{N}_{2} \mathrm{O}$ (Fig. 2b).

Also for vanillic acid in the mixture, the $\mathrm{N}_{2} \mathrm{O}$ atmosphere promote the higher degradation results, but at $\mathrm{pH} 10$.

Protocatechuic acid was not detected for the assayed conditions at $\mathrm{pH} 10$ in isolated solutions, which could be justified by its dissociation at higher $\mathrm{pH}$ values, as reported by Wang et al. [33]. Also, among the 


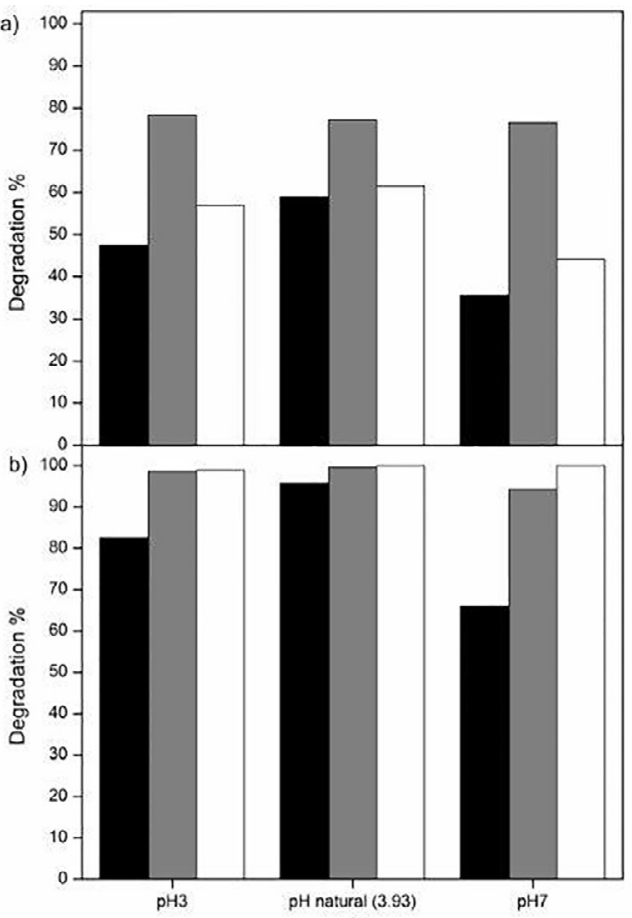

$\mathrm{pH}$

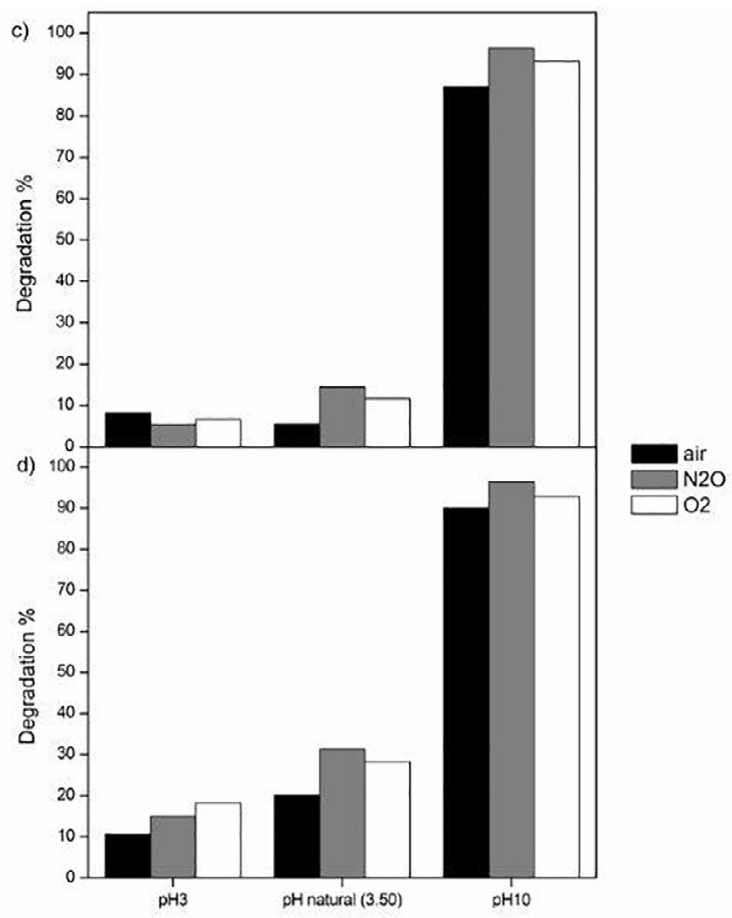

$\mathrm{pH}$

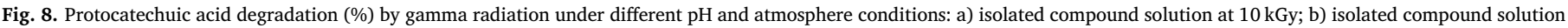
at $20 \mathrm{kGy}$; c) quaternary mixture solution at $10 \mathrm{kGy}$; d) quaternary mixture solution at $20 \mathrm{kGy}$.
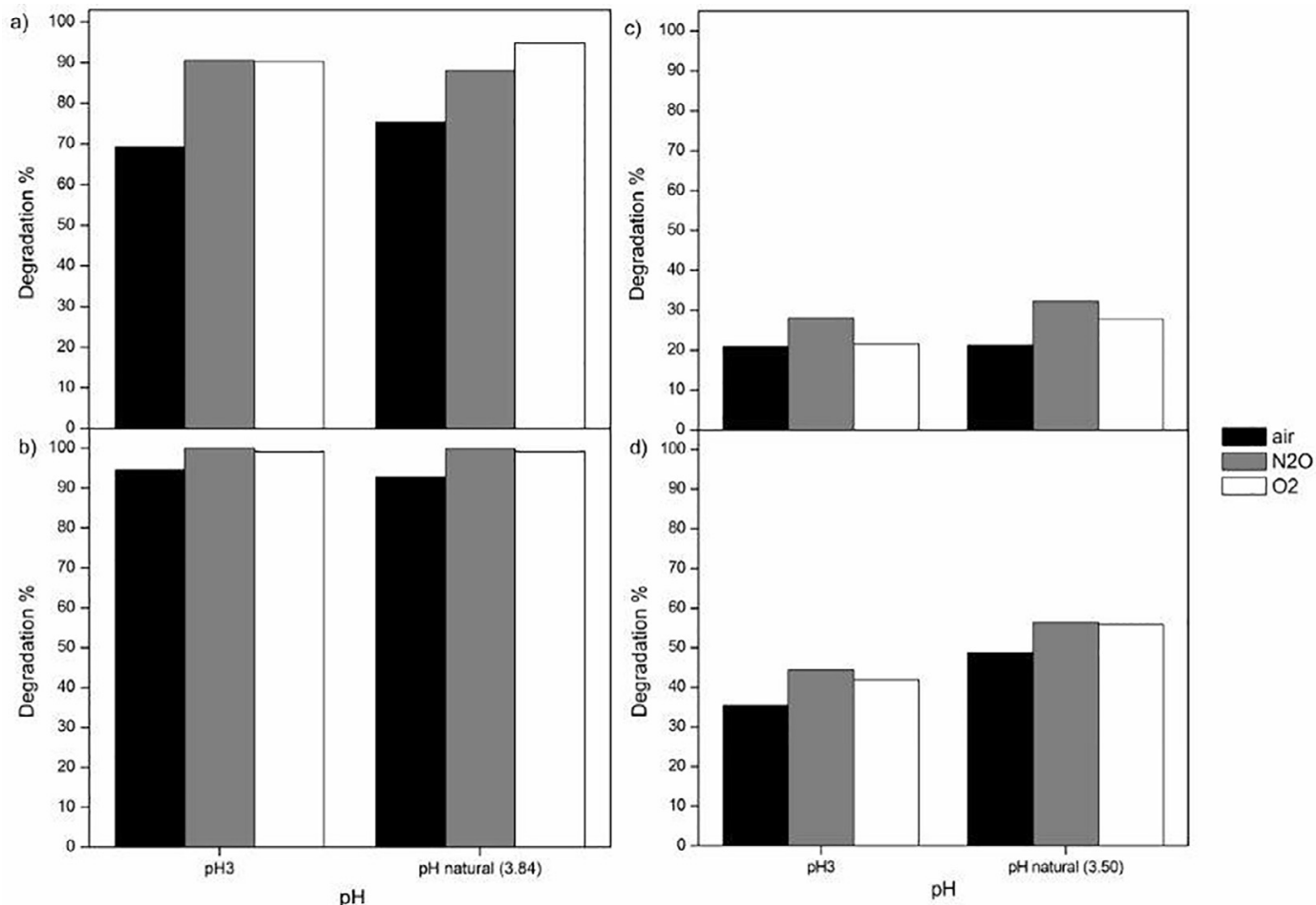

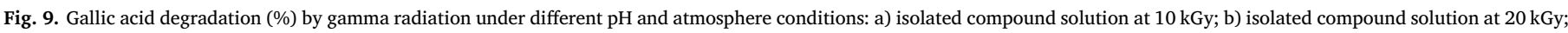
c) quaternary mixture solution at $10 \mathrm{kGy}$; d) quaternary mixture solution at $20 \mathrm{kGy}$.

studied four phenolic compounds, protocatechuic acid was the one that presented different trends in the mixture solution (Fig. 4b). Contrarily to the other phenolic acids, at $\mathrm{pH} 10$ it was observed for this compound high values of degradation ( $>90 \%$ ) even at relatively lower doses ( $5 \mathrm{kGy}$ ). This effect was not expected since alkaline conditions usually promotes a decrease on the degradation efficiency due to a reduction on reactive species formation [29]. A protective effect of protocatechuic acid in the mixture solution, combined to its instability at higher $\mathrm{pH}$, is the proposed hypothesis to justify the observed sudden degradation at $\mathrm{pH}$ 10. However, at pH 7 it was verified a slightly increase in its concentration with the increase of gamma radiation dose. Probably, this effect could be attributed to the radiolytic decomposition of the other 


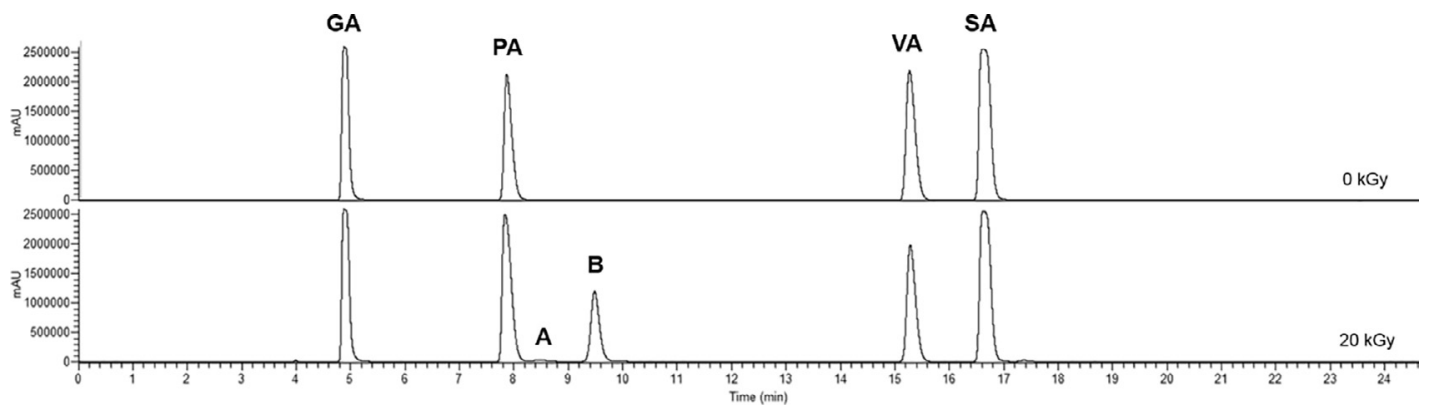

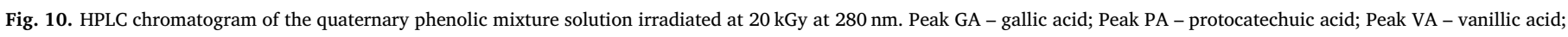
Peak SA - syringic acid; Peaks A and B - detected radiolytic products.

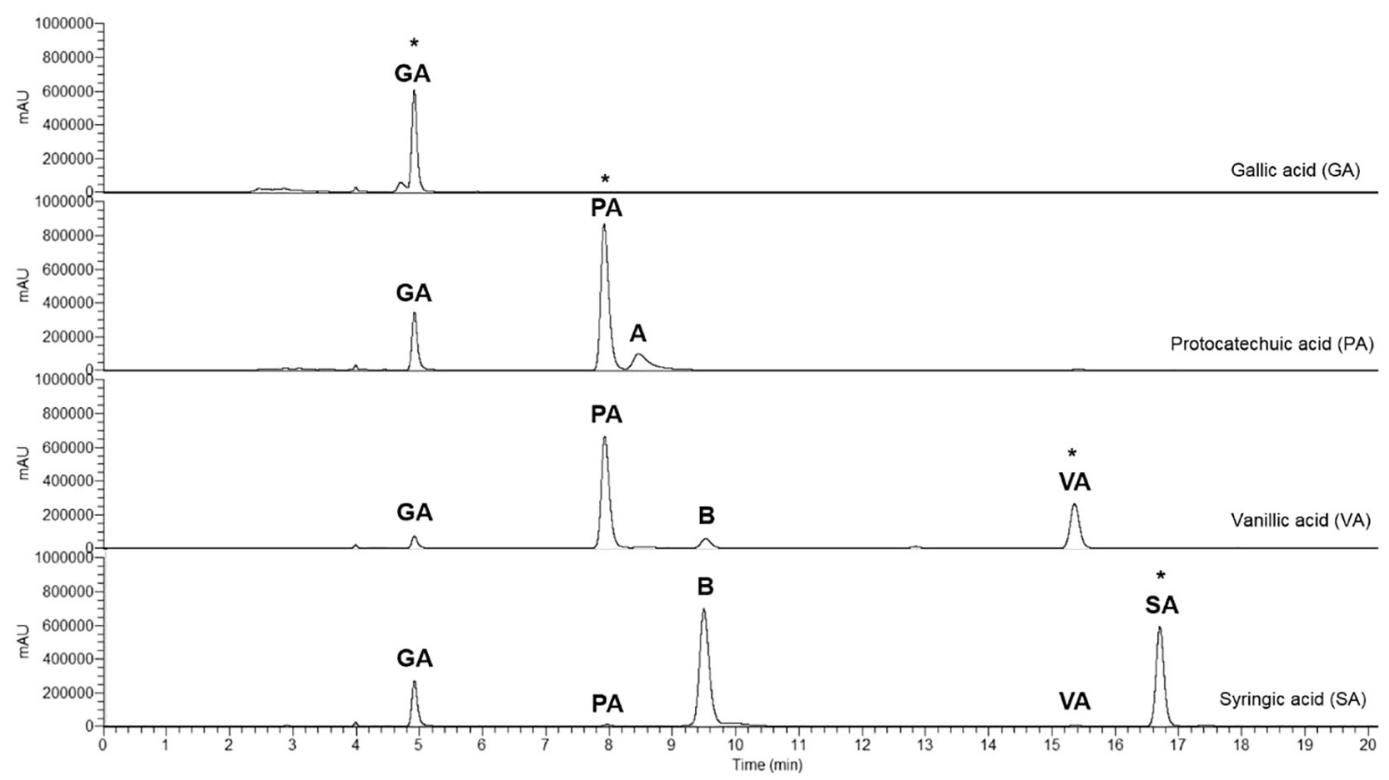

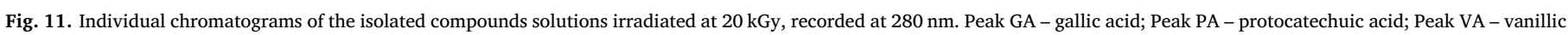
acid; Peak SA - syringic acid; Peaks A and B - detected radiolytic products. The symbol * refers to the compound that is being studied.

\section{SA}

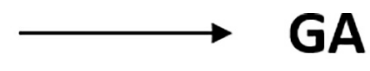

$\downarrow$

\section{VA}

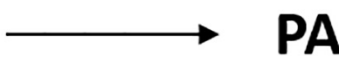

Fig. 12. Schematic representation of the degradation of phenolic acids: GA - gallic acid; PA - protocatechuic acid; VA - vanillic acid; SA - syringic acid; A and B - detected radiolytic products.

phenolic acids into protocatechuic acid, as this is the simplest compound. This hypothesis will be discussed in Section 3.2.

Gallic acid was also not detected for the assayed conditions at $\mathrm{pH} 7$ and 10, due to its instability at higher $\mathrm{pH}$, as previously reported [34]. In the mixture of the four phenolic acids (Fig. 5b), the gallic acid degradation was also greater for the solutions saturated with $\mathrm{N}_{2} \mathrm{O}(\mathrm{pH}$ natural), as was similarly observed for the other compounds.

Considering the obtained results in the quaternary mixture, the solutions saturated with $\mathrm{N}_{2} \mathrm{O}$ indicated an improvement of the radiolytic degradation of all phenolic acids. The $\mathrm{pH}$ of the quaternary mixture suggested to have distinct influence on the decomposition of the target compounds.

The obtained degradation efficiencies (\%) of the four phenolic compounds in isolated and mixture solutions for the two applied doses $9.9 \mathrm{kGy}$ and $19.7 \mathrm{kGy}$ are represented in Figs. 6-9. Further on, the mentioned gamma radiation doses will be assumed as 10 and $20 \mathrm{kGy}$ for simplicity.

For the isolated compounds (Figs. 6a-b, 7a-b, 8a-b, 9a-b), a decrease of phenolics concentrations higher than $36 \%$ was observed. Moreover, the degradation efficiencies of the individual solutions irradiated at $10 \mathrm{kGy}$ (Figs. 6a, 7a, 8a, 9a) suggested, in general, highest decomposition $(77 \%$ to $95 \%)$ under saturated $\mathrm{N}_{2} \mathrm{O}$ and at natural $\mathrm{pH}$. The higher degradation under $\mathrm{N}_{2} \mathrm{O}$ atmosphere was previously described [35], being related with the increase of $\mathrm{OH}$ radical due to the conversion of $e_{a q}^{-}$to ${ }^{\circ} \mathrm{OH}$ as shown in Eq. (2).

$$
\mathrm{e}_{\mathrm{aq}^{-1}}^{-}+\mathrm{N}_{2} \mathrm{O}+\mathrm{H}_{2} \mathrm{O} \rightarrow \mathrm{OH}+\mathrm{N}_{2}+\mathrm{OH}^{-} \quad \mathrm{k}=9.1 \times 10^{9} \mathrm{~L} \mathrm{~mol}^{-1}
$$

Under this condition, the concentration of ' $\mathrm{H}$ is ten times lower than the concentration of ${ }^{\circ} \mathrm{OH}$, turning it in the main radical that reacts with the compounds.

Conversely, the lowest degradation $(\leq 79 \%)$ for the isolated compounds at $10 \mathrm{kGy}$ were obtained in air independently of $\mathrm{pH}$. Otherwise, increasing the absorbed dose (20 kGy) (Figs. 6b, 7b, 8b, 9b), the aerated solutions at natural $\mathrm{pH}$ reached similar degradation ( $>90 \%$ ) in comparison with the other conditions, which could be relevant for the treatment application. 
a)

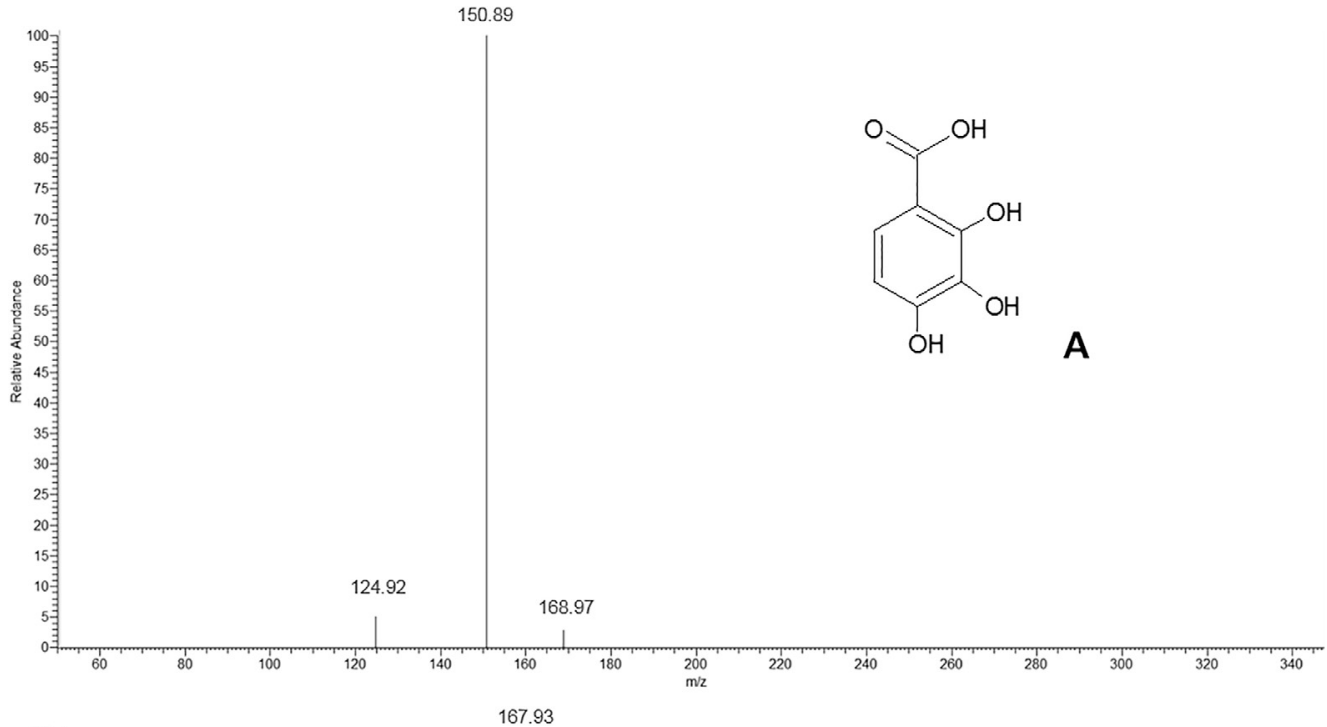

b)

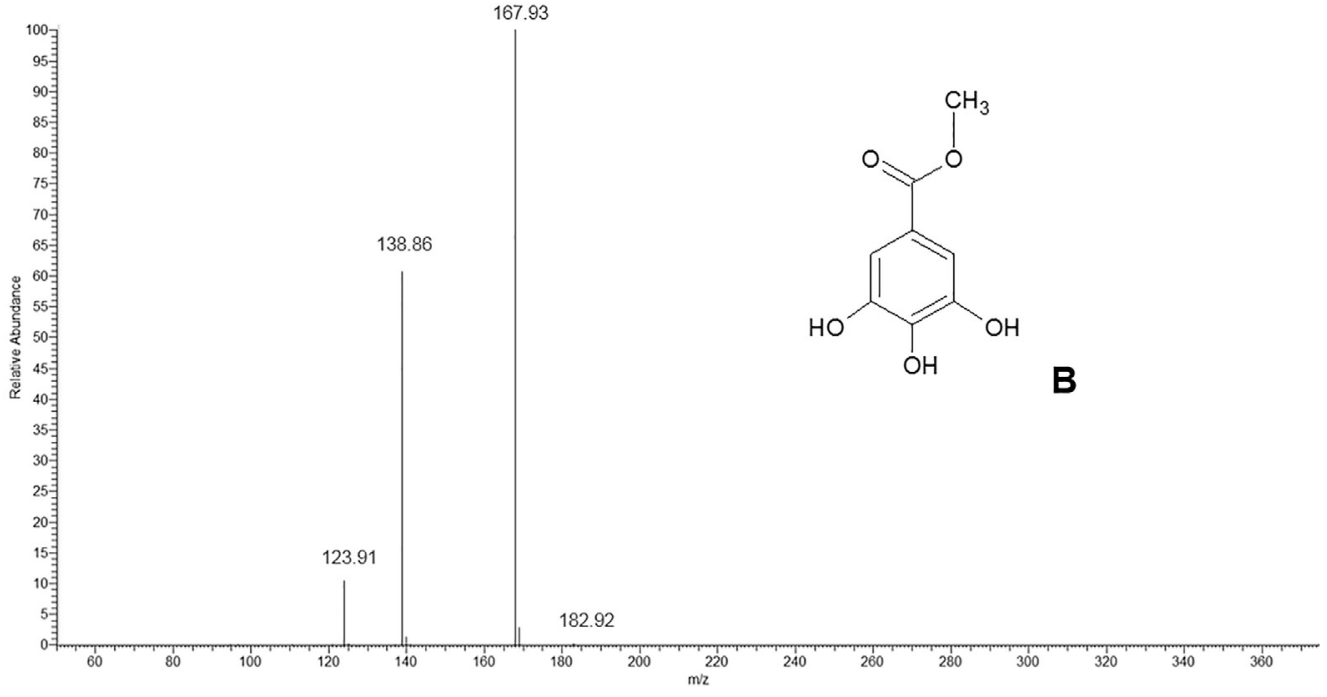

Fig. 13. MS fragmentation spectra of a) 2,3,4-trihydroxybenzoic acid (Peak A of Figs. 3 and 4 chromatograms) and b) methyl gallate (Peak B of Figs. 3 and 4 chromatograms).

Other authors performed a comparison of the efficiency of the total removal of gallic acid using several chemical oxidation systems, namely UV irradiation, UV/ $\mathrm{H}_{2} \mathrm{O}_{2}$, Fenton's reagent and photo-Fenton system, being this last the most efficient method with degradations higher than $93 \%$ at $\mathrm{pH} 3$ and at least 40 min of reaction [19]. Furthermore, it was also reported that the combination of ozone and UV radiation leads to degradation of syringic and vanillic acids higher than $98 \%$, compared with the results obtained with single UV radiation $(<24 \%)$, due to the action of hydroxyl radicals generated from the synergistic effect of both oxidant agents [22]. Moreover, the photocatalytic degradation of protocatechuic acid has been investigated in aqueous heterogeneous solutions containing semiconductor powders $\left(\mathrm{TiO}_{2}, \mathrm{ZnO}\right)$ as photocatalysts, both in the presence of artificial and natural illumination [36]. Among them, ZnO have shown the highest photocatalytic activity presenting mineralization rates for protocatechuic acid of $90 \%$ after $100 \mathrm{~min}$ of UV irradiation [36]. Similar degradation efficiencies for the studied four phenolic acids (degradation percentage at $20 \mathrm{kGy}$ between $93 \%$ and $100 \%$ ) were obtained in the present study using at natural $\mathrm{pH}$ only one advanced oxidation technology, as gamma radiation, without requiring the addition of any chemicals.

Regarding the quaternary mixture solution (Figs. 6c-d, 7c-d, 8c-d, $9 \mathrm{c}-\mathrm{d})$, the gamma radiation dose of $10 \mathrm{kGy}$ was not efficient to degrade $(<60 \%$, except for protocatechuic acid at $\mathrm{pH} 10)$ the compounds for any assayed condition. Nevertheless, increasing the treatment dose to $20 \mathrm{kGy}$ and at natural $\mathrm{pH}$ it was possible to attain a degradation of at least $50 \%$ for the compounds, with exception of protocatechuic acid.

The differential degradation by advanced oxidation processes of substances in a mixture from the single substance was previously reported, highlighting that degradation rates cannot easily be predicted in a complex matrix [37]. Also corroborating our results, a study using Photo-Fenton reaction to degrade a mixture of five soluble phenolic compounds to simulate complex matrix as real wastewater, verified that the degradation of protocatechuic acid was the slowest of the five [37].

Considering the obtained results, ionizing radiation applied at a dose of $20 \mathrm{kGy}$ without adding chemicals [38] could be an alternative treatment procedures for industrial wastewater with phenolic content.

\subsection{Identification of degradation products}

Based on the previous results, the natural $\mathrm{pH}$ was selected as the most feasible condition to be used for the degradation of the studied phenolic acids in the quaternary mixture, since considerable degradation results were obtained for all the phenolic acids without the further cost of chemicals addition. Concerning the irradiation atmosphere, the differences between the aerated and the $\mathrm{O}_{2}$ or $\mathrm{N}_{2} \mathrm{O}$ saturated solutions at natural $\mathrm{pH}$ were not so high that could justify the higher cost of using different atmospheres to promote different radical species for the compounds degradation. Taking this information into account, the identification of the degradation products of the studied phenolic acids was performed for the aerated solutions and at natural $\mathrm{pH}$. 


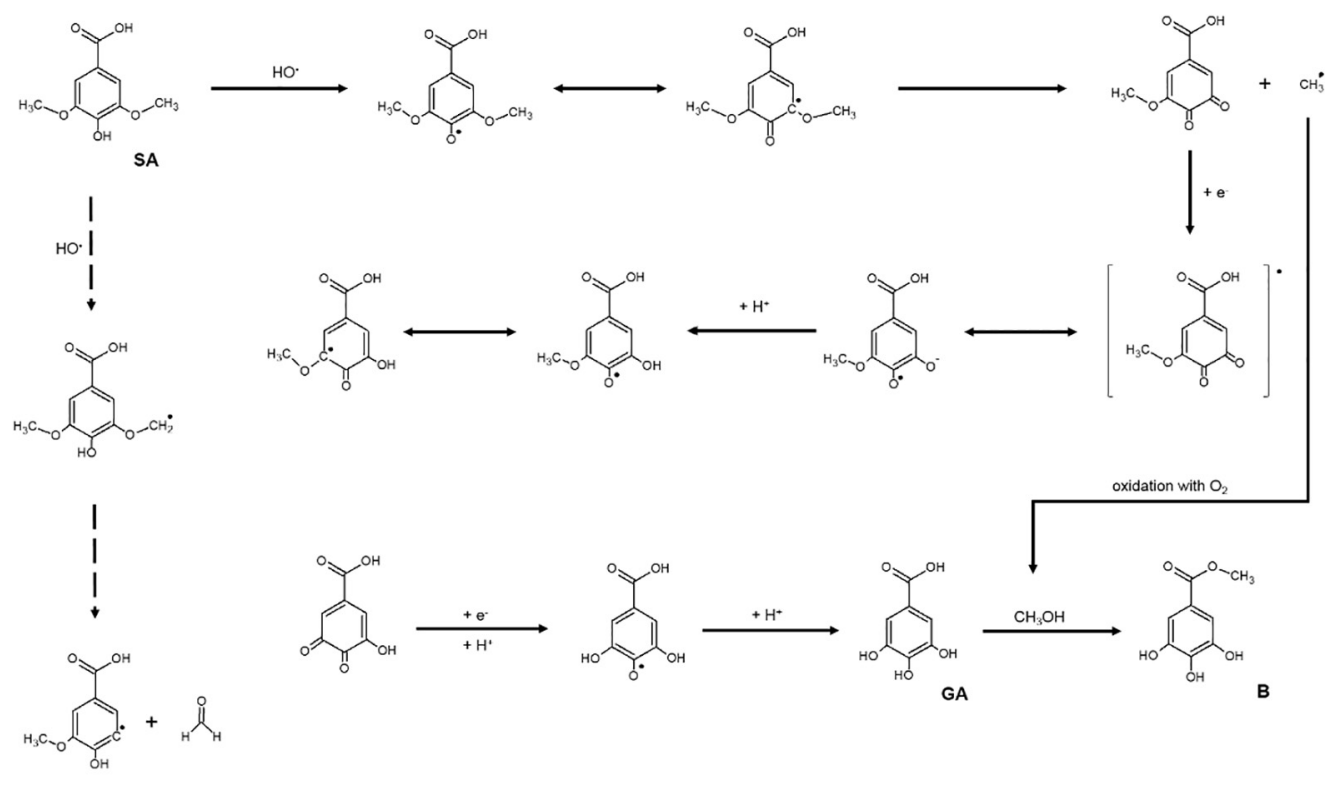<smiles>I[I-]I</smiles>

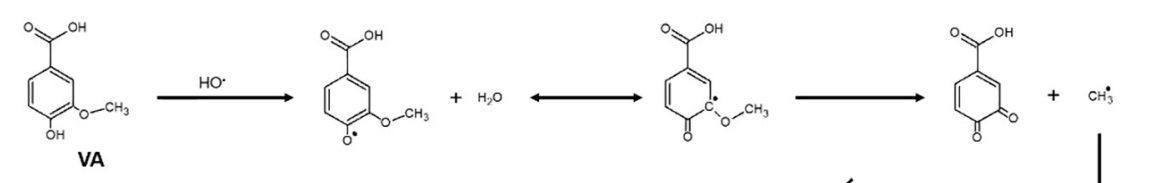

VA

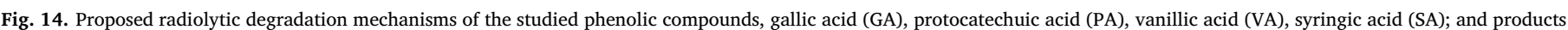

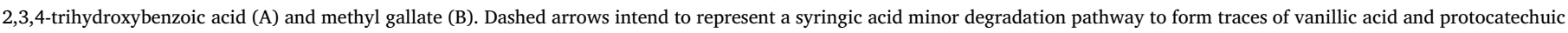
acid. Note: The formation of methyl gallate (ester derivative of gallic acid) is possible in the presence of $\mathrm{MeOH}$.

Fig. 10 represents the HPLC chromatogram of the quaternary mixture solution irradiated at $20 \mathrm{kGy}$.

It is important to mention that, at an irradiation dose of $20 \mathrm{kGy}$ in the natural conditions (natural $\mathrm{pH}$ and in air), gallic acid (peak GA, $\mathrm{R}_{\mathrm{t}}=4.89 \mathrm{~min}$ ), protocatechuic acid (peak PA, $\mathrm{R}_{\mathrm{t}}=7.84 \mathrm{~min}$ ), vanillic acid (peak VA, $\mathrm{R}_{\mathrm{t}}=15.28 \mathrm{~min}$ ) and syringic acid (peak $\mathrm{SA}$,
$\mathrm{R}_{\mathrm{t}}=16.63 \mathrm{~min}$ ) were still observed because they were not completely degraded in the quaternary mixture solution. This situation was also observed in Figs. 2b-5b which indicated that the degradation was not complete in the natural conditions for any of the compounds at this absorbed dose and that protocatechuic acid concentration increased in the mixture after irradiation. Considering this incomplete degradation, 
it could be hypothesized that some of the studied phenolic acids could be the degradation products of others in the quaternary mixture and, as mentioned before, a radioprotective effect of the compounds could be also occurring. To verify this hypothesis, the individual chromatograms of the isolated phenolic compounds and their degradation products at $20 \mathrm{kGy}$ were overlaid as represented in Fig. 11.

It is observed that the syringic acid was partially degraded into gallic acid, protocatechuic acid and vanillic acid, but a peak for nondegraded syringic acid still remains. For vanillic acid, it was verified an incomplete decomposition into gallic and protocatechuic acids. The protocatechuic acid indicated to be partial fragmented in gallic acid. In addition to the studied phenolic acids, two main gamma radiolytic products (A and B) were detected. A simplified schematic representation of the phenolic acids degradation is presented in Fig. 12.

The peak A $\left(R_{t}=8.45 \mathrm{~min}\right)$ was tentatively identified as 2,3,4-trihydroxybenzoic acid with $[\mathrm{M}-\mathrm{H}]^{-}$at $m / z 169$. The major fragments $\mathrm{m} / z 151$ and 125 were ascribed to the loss of $\mathrm{H}_{2} \mathrm{O}$ and $\mathrm{CO}_{2}$ respectively, from the deprotonated molecular ion (Fig. 13a). The peak B $\left(R_{t}=9.52 \mathrm{~min}\right)$ was identified as methyl gallate (Methyl 3,4,5-trihydroxybenzoate) based on its $[\mathrm{M}-\mathrm{H}]^{-}$ion at $m / z 183$ and $\mathrm{MS}^{2}$ spectrum showing as major fragment ions $m / z 168$ (loss of $\mathrm{CH}_{3}$ ) and 124 (further loss of carboxylic group) (Fig. 13b). The fragmentation of methyl gallate was previously described by Barreto et al. [39].

Based on these results, possible degradation pathways are proposed in Fig. 14. The degradation of syringic acid (SA) and vanillic acid (VA) could form protocatechuic acid (PA) and gallic acid (GA). The methyl radical formed during this degradation, could react with oxygen to form methanol [40], which will react with gallic acid producing methyl gallate (B), a known gallic acid ester derivative. The esterification of gallic acid in the presence of methanol was previously reported by Newsome et al. [41]. The hydroxyl attack to the aromatic ring of protocatechuic acid could promote the formation of 2,3,4-trihydroxybenzoic acid (A) and gallic acid (GA) depending on the position (ortho- or meta-, respectively) of the attack.

\section{Conclusions}

With this work it was possible to study the degradation by gamma radiation of cork phenolic compounds in isolated and mixture aqueous solutions under different conditions of $\mathrm{pH}$ and irradiation atmosphere. It was found that the saturation with $\mathrm{N}_{2} \mathrm{O}$ promoted the highest degradation rates for all phenolic acids in the mixture. However, the $\mathrm{pH}$ effect was not so consistent for the radiolytic degradation of all compounds, being achieved degradation efficiencies higher than $74 \%$ at $\mathrm{pH}$ 7 and $\mathrm{pH} 10$.

The experimental conditions allowed to observe degradation rates higher than $50 \%$ for the phenolic acids in aerated solutions under natural $\mathrm{pH}$ that were irradiated at $20 \mathrm{kGy}$. This output could be relevant for an outcome treatment application, since ionizing radiation at a dose of $20 \mathrm{kGy}$ could be applied under the acceptable range for the wastewater treatment procedures, without the addition of chemicals.

In the quaternary mixture of gallic, protocatechuic, vanillic and syringic acids it was verified a partial degradation of these phenolics by gamma radiation due to its intra-decomposition and radioprotective effect among each other. Moreover, the identities of other two radiolytic products, trihydroxybenzoic acid and methyl gallate, were suggested and the fragmentation pathways of the studied phenolic acids was proposed.

\section{Acknowledgments}

This work was supported by Fundação para a Ciência e a Tecnologia (FCT, Portugal) through financial support of RECI/AAG-TEC/0400/ 2012 "Application of Ionizing Radiation for a Sustainable Environment" project. C2TN/IST authors gratefully acknowledge the FCT support through the UID/Multi/04349/2013 project.Conflicts of interest
None.

\section{References}

[1] M. Bernardo, A. Santos, P. Cantinho, M. Minhalma, Cork industry wastewater partition by ultra/nanofiltration: a biodegradation and valorisation study, Water Res. 45 (2011) 904-912, http://dx.doi.org/10.1016/j.watres.2010.09.027.

[2] A.R. Ribeiro, O.C. Nunes, M.F.R. Pereira, A.M.T. Silva, An overview on the advanced oxidation processes applied for the treatment of water pollutants defined in the recently launched Directive 2013/39/EU, Environ. Int. 75 (2015) 33-51, http://dx.doi.org/10.1016/j.envint.2014.10.027.

[3] J.L. Acero, F.J. Benitez, J.B. De Heredia, A.I. Leal, Chemical treatment of corkprocessing wastewaters for potential reuse, J. Chem. Technol. Biotechnol. 1072 (2004) 1065-1072, http://dx.doi.org/10.1002/jctb.1067.

[4] A.C. Gomes, L. Silva, R. Simões, N. Canto, A. Albuquerque, Toxicity reduction and biodegradability enhancement of cork processing wastewaters by ozonation, Water Sci. Technol. 68 (10) (2013) 2214-2219, http://dx.doi.org/10.2166/wst.2013.478.

[5] M. Dias-Machado, L.M. Madeira, B. Nogales, O.C. Nunes, Treatment of cork boiling wastewater using chemical oxidation and biodegradation, Chemosphere 64 (2006) 455-461, http://dx.doi.org/10.1016/j.chemosphere.2005.11.067.

[6] A.M.F.M. Guedes, L.M.P. Madeira, R.A.R. Boaventura, C.A.V. Costa, Fenton oxidation of cork cooking wastewater - overall kinetic analysis, Water Res. 37 (2003) 3061-3069, http://dx.doi.org/10.1016/S0043-1354(03)00178-7.

[7] F.J. Benítez, J.L. Acero, A.I. Leal, Treatment of wastewaters from the cork process industry by using ultrafiltration membranes, Desalination 229 (2008) 156-169, http://dx.doi.org/10.1016/j.desal.2007.08.016.

[8] J. Oliveira, M. Nunes, P. Santos, P. Cantinho, M. Minhalma, Cork processing wastewater treatment/valorisation by nanofiltration, Desalin. Water Treat. 11 (2009) 224-228, http://dx.doi.org/10.5004/dwt.2009.805.

[9] A.R.S. Teixeira, J.L.C. Santos, J.G. Crespo, Sustainable membrane-based process for valorisation of cork boiling wastewaters, Sep. Purif. Technol. 66 (2009) 35-44, http://dx.doi.org/10.1016/j.seppur.2008.12.001.

[10] E. De Torres-Socías, I. Fernández-calderero, I. Oller, M.J. Trinidad-lozano, F.J. Yuste, S. Malato, Cork boiling wastewater treatment at pilot plant scale: comparison of solar photo-Fenton and ozone (O3, O3/H2O2). Toxicity and biodegradability assessment, Chem. Eng. J. 234 (2013) 232-239, http://dx.doi.org/10.1016/ j.cej.2013.08.072.

[11] C.A. Silva, L.M. Madeira, R.A. Boaventura, C.A. Costa, Photo-oxidation of cork manufacturing wastewater, Chemosphere 55 (2004) 19-26, http://dx.doi.org/10. 1016/j.chemosphere.2003.11.018.

[12] S. Cabo Verde, T. Silva, P. Matos, Effects of gamma radiation on wastewater microbiota, Radiat. Environ. Biophys. (2015), http://dx.doi.org/10.1007/s00411 015-0617-2.

[13] R. Melo, S. Cabo Verde, J. Branco, M.L. Botelho, Gamma radiation induced effects on slaughterhouse wastewater treatment, Radiat. Phys. Chem. (2008), http://dx. doi.org/10.1016/j.radphyschem.2007.03.006.

[14] C. Lima, J. Madureira, R. Melo, M.M. Carolino, J.P. Noronha, F.M.A. Margaça, S. Cabo Verde, A biodegradation bench study of cork wastewater using gamma radiation, J. Adv. Oxid. Technol. 19 (2016) 73-78.

[15] M. Minhalma, M.N. De Pinho, Tannic-membrane interactions on ultrafiltration of cork processing wastewaters, Sep. Purif. Technol. 22-23 (2001) 479-488.

[16] A. Krastanov, Z. Alexieva, H. Yemendzhiev, Microbial degradation of phenol and phenolic derivatives, Eng. Life Sci. 13 (2013) 76-87, http://dx.doi.org/10.1002/ elsc. 201100227.

[17] Commission of the European Communities, Drinking Water Directive 80/778/EEC, 1980. http://eur-lex.europa.eu/legal-content/EN/TXT/PDF/?uri = CELEX:31980L0778\&from $=$ EN

[18] US EPA, National Recommended Water Quality Criteria, n.d. https://www.epa. gov/wqc/national-recommended-water-quality-criteria-aquatic-life-criteria-table (accessed January 3, 2018)

[19] F.J. Benitez, F.J. Real, J.L. Acero, A.I. Leal, C. Garcia, Gallic acid degradation in aqueous solutions by UV/ $\mathrm{H}_{2} \mathrm{O}_{2}$ treatment, Fenton's reagent and the photo-Fenton system, J. Hazard. Mater. 126 (2005) 31-39, http://dx.doi.org/10.1016/j.jhazmat. 2005.04.040.

[20] F.J. Benitez, J. Beltran-Heredia, J.L. Acero, Oxidation of Vanillic acid as a model of polyphenolic compounds in olive oil wastewaters. III. Combined UV radiation-hydrogen peroxide oxidation, Toxicol. Environ. Chem. 56 (1996) 199-210, http://dx doi.org/10.1080/02772249609358363.

[21] F.J. Benitez, J. Beltran-Heredia, J.L. Acero, T. Gonzalez, Degradation of protocatechuic acid by two advanced oxidation processes: ozone/UV radiation and H2O2/UV radiation, Water Res. 30 (1996) 1597-1604.

[22] F.J. Benitez, J. Beltran-Heredia, J.L. Acero, M.L. Pinilla, Simultaneous photodegradation and ozonation plus UV radiation of phenolic acids - major pollutants in agro-industrial wastewaters, J. Chem. Technol. Biotechnol. 70 (1997) 253-260.

[23] M.S. Lucas, A.A. Dias, R.M. Bezerra, J.A. Peres, Gallic acid photochemical oxidation as a model compound of winery wastewaters, J. Environ. Sci. Heal. Part A 43 (2008) 1288-1295, http://dx.doi.org/10.1080/10934520802177904.

[24] F.J. Benitez, J. Beltran-Heredia, J.L. Acero, Protocatechuic acid ozonation in aqueous solutions, Water Res. 27 (1993) 1519-1525, http://dx.doi.org/10.1016/00431354(93)90096-Z.

[25] F.J. Benitez, J. Beltran-Heredia, T. Gonzalez, J.L. Acero, Photochemical oxidation of protocatechuic acid, Water Res. 28 (1994) 2095-2100, http://dx.doi.org/10.1016/ 0043-1354(94)90019-1.

[26] R.P. Melo, J.P. Leal, M.L. Botelho, Radiolytic degradation mechanism of gallic acid and its end-products, Rapid Commun. Mass Spectrom. 25 (2011) 218-222, http:// 
dx.doi.org/10.1002/rcm.4803.

[27] J. Madureira, A.I. Pimenta, L. Popescu, A. Besleaga, M.I. Dias, P.M.P. Santos, R. Melo, I.C.F.R. Ferreira, S. Cabo Verde, F.M.A. Margaça, Effects of gamma radiation on cork wastewater: antioxidant activity and toxicity, Chemosphere 169 (2017) 139-145, http://dx.doi.org/10.1016/j.chemosphere.2016.11.064.

[28] J. Madureira, R. Melo, M.L. Botelho, J.P. Leal, I.M. Fonseca, Effect of ionizing radiation on antioxidant compounds present in cork wastewater, Water Sci. Technol. 67 (2) (2013) 374-379, http://dx.doi.org/10.2166/wst.2012.544.

[29] J.W.T. Spinks, R.J. Woods, An Introduction to Radiation Chemistry, Third, John Wiley \&. Sons, Inc, New York, 1990.

[30] B. Whittaker, M.F. Watts, The influence of dose rate, ambient temperature and time on the radiation response of Harwell PMMA dosimeters, Radiat. Phys. Chem. 60 (2001) 101-110, http://dx.doi.org/10.1016/S0969-806X(00)00316-9.

[31] American Society for Testing and Materials, Practice for Using the Fricke Reference Standard Dosimetry System, 12.02, Philadelphia, PA, 1992.

[32] L. Barros, E. Pereira, R.C. Calhelha, M. Dueñas, A.M. Carvalho, C. Santos-Buelga, I.C.F.R. Ferreira, Bioactivity and chemical characterization in hydrophilic and lipophilic compounds of Chenopodium ambrosioides L. J. Funct. Foods. 5 (2013) 1732-1740, http://dx.doi.org/10.1016/j.jff.2013.07.019.

[33] C. Wang, M. Niu, M. Liu, D. Sun, B. Wang, Z. Wang, D. Li, G. Liu, J. Han, Solvent and $\mathrm{pH}$ dependences of mixing enthalpies of $\mathrm{N}$-glycylglycine with protocatechuic acid, J. Chem. Eng. Data 61 (2016) 487-494, http://dx.doi.org/10.1021/acs.jced. 5 b00666.

[34] M. Friedman, H.S. Jü, Effect of pH on the Stability of Plant Phenolic Compounds, (n. d.). doi: $10.1021 /$ jf $990489 j$.

[35] M. Sayed, L.A. Shah, J.A. Khan, N.S. Shah, H.M. Khan, R.A. Khan, A.R. Khan, A.M. Khan, Hydroxyl radical based degradation of ciprofloxacin in aqueous solution, J. Chil. Chem. Soc. 61 (2016) 2949-2953, http://dx.doi.org/10.4067/S0717 97072016000200019

[36] I. Poulios, D. Makri, X. Prohaska, Photocatalytic treatment of olive milling waste water: oxidation of protocatechuic acid, Glob. Nest Int. J. 1 (1999) 55-62.

[37] W. Gernjak, T. Krutzler, A. Glaser, S. Malato, J. Caceres, R. Bauer, A.R. Fernandez Alba, Photo-fenton treatment of water containing natural phenolic pollutants, Chemosphere 50 (2003) 71-78, http://dx.doi.org/10.1016/S0045-6535(02) 00403-4.

[38] B.H. Moon, Y.B. Park, K.H. Park, Fenton oxidation of Orange II by pre-reduction using nanoscale zero-valent iron, Desalination 268 (2011) 249-252, http://dx.doi. org/10.1016/j.desal.2010.10.036.

[39] J.C. Barreto, M.T.S. Trevisan, W.E. Hull, G. Erben, E.S. De Brito, B. Pfundstein, G.W. Rtele, B. Spiegelhalder, R.W. Owen, Characterization and quantitation of polyphenolic compounds in bark, kernel, leaves, and peel of mango (Mangifera indica L.), J. Agric. Food Chem. 56 (2008) 5599-5610, http://dx.doi.org/10.1021/ jf800738r.

[40] M.M. Halmann, Hydrocarbon derivates, in: M.M. Halmann (Ed.), Photodegradation Water Pollut. CRC Press, Bosa Roca, United States, 1996, pp. 67-97.

[41] A.G. Newsome, Y. Li, R.B. Van Breemen, Improved quantification of free and esterbound gallic acid in foods and beverages by UHPLC-MS/MS, J. Agric. Food Chem. 64 (2016) 1326-1334, http://dx.doi.org/10.1021/acs.jafc.5b04966. 